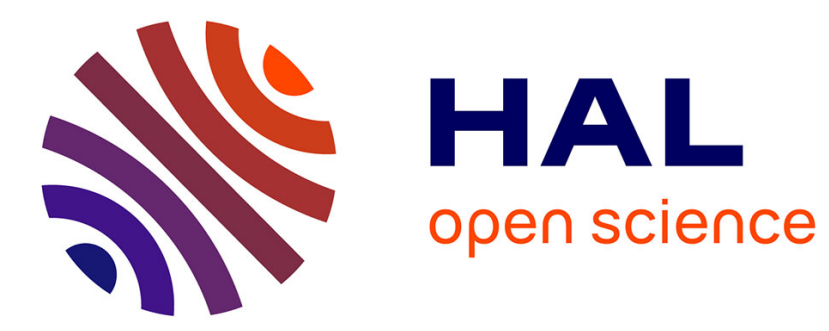

\title{
Fight Cartels or Control Mergers? On the Optimal Allocation of enforcement Efforts within Competition Policy
}

Andreea Cosnita, Jean-Philippe Tropeano

\section{- To cite this version:}

Andreea Cosnita, Jean-Philippe Tropeano. Fight Cartels or Control Mergers? On the Optimal Allocation of enforcement Efforts within Competition Policy. International Review of Law and Economics, 2013, 34, pp.34-40. 10.1016/j.irle.2012.10.002 . hal-00977619

HAL Id: hal-00977619

https://hal.science/hal-00977619

Submitted on 11 Apr 2014

HAL is a multi-disciplinary open access archive for the deposit and dissemination of scientific research documents, whether they are published or not. The documents may come from teaching and research institutions in France or abroad, or from public or private research centers.
L'archive ouverte pluridisciplinaire HAL, est destinée au dépôt et à la diffusion de documents scientifiques de niveau recherche, publiés ou non, émanant des établissements d'enseignement et de recherche français ou étrangers, des laboratoires publics ou privés. 


\title{
Fight Cartels or Control Mergers? \\ On the Optimal Allocation of Enforcement Efforts within Competition Policy
}

\section{Andreea Cosnita-Langlais* and Jean-Philippe Tropeano ${ }^{\dagger}$}

\author{
November 1, 2012
}

\begin{abstract}
This paper deals with the optimal enforcement of competition law between merger and anti-cartel policies. We examine the interaction between these two branches of antitrust, given the budget constraint of the public agency, and taking into account the ensuing incentives for firms in terms of choice between cartels and mergers. To the extent that a tougher anti-cartel action triggers more mergers and vice-versa, we show that the two antitrust branches are complementary. However, if the merger's coordinated effect is taken into account, then for a sufficiently large such effect the agency may optimally have to refrain from controlling mergers and instead spend all resources on fighting cartels.
\end{abstract}

Keywords: competition law enforcement, antitrust, merger control, anti-cartel policy

JEL classification: L41, K21, D82

\footnotetext{
*Université Paris Ouest Nanterre La Défense and EconomiX - UMR CNRS 7235; acosnita@u-paris10.fr; Corresponding author: +33(0)140977786, 200 Av.de la République, 92001 Nanterre, France.

${ }^{\dagger}$ Université de Paris 1 and Paris School of Economics; tropeano@univ-paris1.fr

${ }^{\ddagger}$ We wish to thank the editor and two referees for their comments. We are also endebted to Lars Sørgard, Kenneth Fjell, Tomaso Duso and Joe Seldeslachts for their helpful remarks and suggestions. We equally benefitted from those from the participants at the ACLE 2009 meeting in Amsterdam, the 2010 CRESSE Congress in Crete, the 2010 EARIE Conference in Istanbul, as well as the Department of Economics Seminar at the NHH in Bergen and the Faculty of Economics Seminar at the University of Vienna. All remaining errors are ours
} 


\section{Introduction}

Competition authorities address the challenge of anticompetitive horizontal agreements by both controlling mergers and fighting cartels. Under the realistic assumption of a limited budget for the public agency, one may ask how much should be spent on fighting cartels as compared with controlling mergers. Taking into account the incentives thus provided to firms, in this paper we develop a very simple framework to determine the optimal competition policy mix between merger control and cartel fighting.

Firms have been known to adapt their behavior to past decisions of the competition agency. The most famous example is probably that of the Sherman Act, which, in the words of Mueller (1996), "ironically, by prohibiting cartels, encouraged firms to combine [...] and thus helped precipitate the first great merger wave at the turn of the century"1. Its impact on the first merger wave was empirically confirmed by Bittlingmayer (1985). More recently, and based on the analysis of duration for a sample of international cartels prosecuted in the 1990s, Evenett et al. (2001) found that joint ventures and mergers are adopted by firms in cartel-prone industries where cartel formation is restricted. The following real-life example supports this statement: in 2005 the three main players on the French local urban transport markets were fined for partaking in an anti-competitive agreement to share the public transport market of urban bus services during calls for tender ${ }^{2}$. As a result, two of them, Transdev and Veolia, changed plans and five years later notified a horizontal merger, which was granted conditional approval by the French Competition Authority at the end of $2010^{3}$.

In our model we first discuss the case of this apparent substitutability between mergers and cartels. Then we also consider their complementarity, i.e. the case where firms merge before engaging in collusion. This possibility is explicitly taken into account by the competition agencies, which are bound to assess a merger's coordinated effect during its overall competitive appraisal $^{4}$. Nonetheless, merger control being prone to errors, firms may sometimes still take the opportunity to collude after having merged. For instance, on November 9, 2010, the European Commission fined 11 air cargo carriers $€ 799$ million for a price fixing cartel that spanned over

\footnotetext{
${ }^{1}$ This American example was later 'confirmed' in the UK by the Restrictive Trade Practices Act of 1956, which similarly triggered a merger wave by outlawing cartels - see Symeonidis (2002).

${ }^{2}$ See decision 05-D-38 of July 5, 2005, available on the site of the Autorite de la Concurrence.

${ }^{3}$ See decision 10-DDC-198 of December 30, 2010, also available on the site of the Autorité de la Concurrence.

${ }^{4}$ See for instance the European Commission's Horizontal Merger Guidelines - OJ C 31/5, from 5.2.2004, paragraphs 39 to 57 .
} 
six years on the European cargo services market, from December 1999 to 14 February $2006^{5}$. Interestingly enough, most of the European airlines involved (such as British Airways, AirFranceKLM, SAS and Lufthansa-Swiss Air) had previously engaged in several successive mergers on the European airfreight market ${ }^{6}$, all of which had gained approval from the European Commission ${ }^{7}$.

We start by discussing the firms' choice to coordinate, and consider first that they can either form a cartel or undertake a horizontal merger. The relative profitability of the two options will depend on the probability of a cartel being convicted, as well as on the net private gains from mergers. Cartel fighting is imperfect in our model, as not all cartels are punished, and the probability of convicting a cartel will depend on the amount of resources allocated for this purpose. This amount will therefore capture the severity of this action. The enforcement of merger control is also imperfect, since the ex ante assessment of horizontal mergers inevitably gives rise to both types of errors, i.e. clearing welfare-reducing anti-competitive mergers and banning cost-efficient pro-competitive ones. This is mainly due to the asymmetric information between the competition agency and the merging partners on the true level of the merger's potential cost savings. Accordingly, in our model the competition agency (CA henceforth) may be able to identify and prohibit anti-competitive mergers provided it pays the cost of doing so. The more resources invested in the merger control the higher the probability of identifying anticompetitive mergers. The latter will thus capture the severity of merger control in our model. At any rate, given the limited budget of the CA, devoting more resources to fighting cartels will prevent it from applying a stricter merger control, and vice-versa.

Explicitly, the trade-off we put forward in this framework is the following. The money spent on controlling mergers enables the CA to screen them and thus avoid some welfare losses from the inefficient, anti-competitive mergers. We call this a selection effect. But this effect comes at the cost of less intense cartel fighting. This is a welfare-reducing effect, which we call the detection effect. We derive our results from the net outcome of these two effects in terms of relative returns for the two instruments of the competition policy, merger control and cartel

\footnotetext{
${ }^{5}$ See the European Commission's press release IP/10/1487.

${ }^{6}$ See the cases M.157/1992, M.259/1992, M.278/1993, M.562/1995, M.616/1995, M.967/1997, M.1128/1998, M.1328/1999, M.1696/1999, M.2672/2002 and the joint-venture M/2830/2002.

${ }^{7}$ Ironically, when clearing the GF-X joint venture for an air freight trading platform between several European airlines (Lufthansa, Air France, British Airways and Global Freight Exchange Limited - see case M.2830/2002), the European Commission declared that the joint venture was set up in such a way that it would not lead to any co-ordination of the competitive conduct of the parent companies on the market for air freight transport - see the European Commission's press release IP/02/1560 from October 28, 2002.
} 
fighting. First of all we show that the two instruments, the control of mergers and the fight against cartels, are complementary, and thus the CA will always optimally spend money on both branches of competition policy. This result may no longer hold when one takes into account the merger's coordinated effect, i.e. its impact on post-merger market collusion. This materializes as a higher likelihood for a cartel to be formed and sustained after a horizontal merger, and therefore makes the firms' strategies of merger and cartel complements. To account for this, we allow the firms to choose between forming a cartel from the beginning, or merging first and later on forming a more stable cartel. In this case, and for a significant enough coordinated effect of the merger, the best way for the CA to tackle post-merger collusion is to fight cartels rather than ban mergers.

This is to our knowledge the first research paper to examine the optimal competition law enforcement mix between merger control and cartel fighting. In a related but different context, Aubert and Pouyet (2004) dealt with the relationship between cartel-fighting and sectorial regulation $^{8}$. As far as antitrust and merger control are concerned, the only theoretical contribution, albeit from a positive perspective, is that of Mehra (2008), which deals with firms' choice between merger and cartel depending on the severity of the anti-cartel action (the fine in case the cartel is detected).

The rest of the paper is structured as follows. We first present the benchmark case of our analysis, then extend it to take into account the merger's coordinated effect. Each time we first discuss the optimal strategies of the firms and the CA, then establish the optimal policy mix between merger control and cartel fighting. All formal proofs are grouped at the end of the paper in a technical appendix.

\section{Model}

Consider the following setting in which the CA has a budget of size $r$ and chooses the amount of resources to be spent on fighting cartels and controlling mergers. The market consists of three identical firms: two of them may engage in a horizontal merger ${ }^{9}$, or the whole industry may

\footnotetext{
${ }^{8}$ See also Bensaid et al. (1995), who investigate the optimality of having a unique antitrust authority to deal with both cartel and mergers, or whether it is on the contrary best to separate the two on account of strategic information and incentive issues.

${ }^{9}$ More precisely, we consider a framework where the opportunity to merge is exogenous and the two firms that contemplate this move are the only ones that may do so, for instance due to some technological complementarity. Thus we leave aside the outsider's incentives to either merge with them or preempt the merger, since we do not
} 
instead form a cartel ${ }^{10}$. The group of two firms is considered as a single player and we assume risk-neutrality throughout. The cartel is not detected with probability $p_{c}(c)$, where $c$ stands for the amount of resources spent by the CA on fighting cartels, with $p_{c}^{\prime}(\Delta)<0, p_{c}^{\prime \prime}(\Delta)=0$, $p_{c}(0)=1$ and $p_{c}(r)=0$. In other terms we assume that if the CA concentrates all its resources on cartel fighting, it detects cartels with certainty, whereas if no resources are dedicated to fighting cartels, there is no cartel detection at all. The cartel provides a joint collusive payoff of $\pi^{C}$ for the two firms which may alternatively engage in a horizontal merger. We do not explicitly formalize the cartel formation but the cartel stability is captured by the size of the profit $\pi^{C}$ earned if the cartel is not detected. The higher this profit, the higher the cartel stability. If the cartel is detected, which occurs with probability $1-p_{c}(c)$, the ensuing payoff for the same two firms will be the competition joint profit $\pi$, where $\pi<\pi^{C}$. Note that we do not explicitly use cartel fines, but their role is captured by the lower profit made by the firms in case of successful detection.

The horizontal merger on the other hand is not only a legal means of achieving coordination, but also a source of cost savings or efficiency gains, denoted by $e$. The joint profit earned for the two firms engaging in the merger is then equal to $\pi^{M}(e)$. For the sake of simplicity, we assume that there are only two types of cost savings, either high $(e=\bar{e})$, giving rise to an 'efficient merger', or low $(e=\underline{e}<\bar{e})$, giving rise to an 'inefficient merger'. Both types occur with equal probability, and the higher the efficiency gains, the more profitable the merger: $\pi^{M}(\bar{e})>\pi^{M}(\underline{e})$. We assume that the efficiency gains parameter $e$ is a priori not observed by the CA, but the latter may however invest $m=r-c$ in merger control in order to investigate the merger project and thus observe the true level of efficiency gains with probability $p_{m}(m)$. By symmetry with the cartel fighting we assume $p_{m}^{\prime}(m)>0, p_{m}^{\prime \prime}(m)=0, p_{m}(0)=0$ and $p_{m}(r)=1$. If the true type of the merger is not observed, the merger is not investigated, and if so, the merger is permitted ${ }^{11}$. Finally, the merging firms incur a fixed cost $k$ in order to merge. This assumption captures the fact that coordination through merger is likely to be costlier than through collusion, or at any rate that merging requires a sunk cost as compared with forming and maintaining a cartel ${ }^{12}$. Firms are however heterogeneous w.r.t. the cost of merging, and we assume that this cost is

propose to deal with this aspect of endogenous merger analysis.

${ }^{10}$ We assume for the time being that the merged entity and the remaining firm cannot form a cartel afterwards. Such a post merger cartel will be studied in the last section.

${ }^{11}$ We follow here Sørgard (2009).

${ }^{12}$ The point worth stressing is that the cartel formation does not require a structural change in the organization of the partners. 
uniformly distributed on the interval $[0, \bar{k}]$. We also assume that $\bar{k}$ is high enough to avoid trivial cases where the firms always merge $\left(\pi^{M}(\underline{e})-\pi^{C}<\bar{k}\right)$, and low enough to induce all firms to have incentives to merge if the cartel is always detected $\left(\pi^{M}(\underline{e})-\pi>\bar{k}\right)$.

In terms of competition policy, the CA maximizes the expected consumer surplus from both fighting cartels and controlling mergers ${ }^{13}$. Let $w^{C}$ denote consumers' welfare following a successful cartel, and $w$ the status-quo competition welfare without any coordinated behavior whatsoever, with $w^{C}<w$. Concerning the merger policy, the post-merger consumer welfare is equal to $w^{M}(e)$, where $w^{M}(\bar{e})>w^{M}(\underline{e})$, meaning that the more efficiency gains the higher the consumer surplus. Moreover, the efficient merger is welfare-improving $\left(w^{M}(\bar{e})>w\right)$, whereas the inefficient merger is welfare-reducing $\left(w^{M}(\underline{e})<w\right)^{14}$. However we assume this inefficient merger to be still preferable to the cartel $\left(w^{C}<w^{M}(\underline{e})\right)$, due to the presence of efficiency gains. For ease of exposition and without any loss of generality, we focus on the possible trade-off between cartel and horizontal merger for the inefficient merger projects only, so we assume that the efficient merger is always more profitable than the cartel: $\bar{k}<\pi^{M}(\bar{e})-\pi^{C}$. The policy choice under budget constraint will consist in determining the optimal spending on merger control and cartel fighting respectively, i.e. the one that maximizes expected consumer surplus ${ }^{15}$.

The timing of the game will be the following (see the game tree below, starting with the second stage):

At the first stage the CA chooses how much to spend on controlling mergers $(m)$ and fighting cartels $(c)$ respectively.

At the second stage Nature determines the type of merger.

At the third stage, the firms make their coordination choice between horizontal merger and collusive behavior. If the merger is chosen, they notify it to the CA.

At the final stage, notified mergers are cleared or banned. If there is no merger, then the cartel is convicted with probability $1-p_{c}(c)$ and the market is forced back to its status-quo

\footnotetext{
${ }^{13}$ In practice, mergers get cleared or banned depending on the expected competitive impact, which is basically assessed in terms of expected post-merger price variation. For instance, the European Commission holds that "a concentration which does not significantly impede competition [...] shall be declared compatible with the common market" - Art.2 of the European Commission Merger Regulation of 29.01.2004.

${ }^{14}$ See Farrell and Shapiro (1990) and Motta (2004) for the welfare-reducing effects of horizontal mergers which do not generate enough efficiency gains, in the case of both Cournot and Bertrand competition.

${ }^{15}$ Although dealing with the CA's optimal activity level in terms of cartel prosecutions, Harrington (2011) mentions the possibility of endogenizing the amount of public resources allocated to cartel fighting by considering a fixed budget that the CA must divide among its various activities, such as prosecuting cartels, controlling mergers and investigating market monopolization.
} 
competition situation. Otherwise, the industry ends up with the collusive market outcome.

\section{Insert Figure 1}

The relevant equilibrium concept is the subgame perfect Nash equilibrium, and in what follows we solve the game backwards.

\section{Optimal competition policy mix}

At the final stage of the game the CA assesses the consumer surplus impact of the merger given the available information on the efficiency gains. At the third stage, when deciding how best to achieve profitable coordination, by merging or by forming a cartel, the group of two firms anticipates the outcome of the CA's merger control decision. This means that the choice between horizontal merger and cartel is determined by the probability of a cartel being detected on the one hand, and the expected merger control decision on the other. The following lemma explains the CA's merger control decision, as well as the choice between cartel and horizontal merger for the group of two firms.

Lemma 1 (i) If the merger is expected to be cleared at the final stage, then the inefficient merging firms decide to merge iff the merger cost $k$ is lower than $\widehat{k}(c)$, where $\widehat{k}(c)$ increases with the amount of resources allocated to cartel fighting $(c)$.

(ii) If the CA observes the merger type, the CA blocks the merger iff the budget available for cartel fighting $(c)$ is larger than a threshold $\widehat{c}$.

To begin with, Lemma 1 states that only the firms with a sufficiently low merging cost will merge. We deduce that the population size of the inefficient merger type increases with the amount of resources invested in fighting cartels. The intuition is straightforward: the more money spent on fighting cartels and thus the higher the probability of cartel detection, the higher the incentives for firms to prefer the merger instead. Thus, the critical merger cost threshold increases with the cartel-fighting expenditure, and thus more firms decide to merge.

Secondly, if the CA observes the true type of merger (with probability $p_{m}(m)$, where $m=$ $r-c)$, it will block the inefficient merger only if enough resources are left for fighting cartels. This is easily explained: a merger will be blocked only if the resulting expected welfare is lower than if the firms are not allowed to merge, which in our model means they will attempt a cartel. Therefore, for a merger to be welfare-reducing in our model, the cartel fighting needs to be 
sufficiently effective, i.e. enough money needs to be spent on detecting and punishing cartels and not too much on merger control.

Going back to the first stage, the CA determines how much to invest in controlling mergers $\left(m^{*}\right)$ and fighting cartels $\left(c^{*}=r-m^{*}\right)$ respectively. Its programme is therefore written as follows:

$$
\begin{aligned}
& \max _{m} E W(m)= \\
& \begin{aligned}
\frac{\widehat{k}(r-m)}{\bar{k}} \cdot\left(\begin{array}{r}
p_{m}(m) \cdot \max \left(w^{M}(\underline{e}),\left[p_{c}(r-m) \cdot w^{C}+\left(1-p_{c}(r-m)\right) \cdot w\right]\right) \\
+\left(1-p_{m}(m)\right) \cdot w^{M}(\underline{e})
\end{array}\right) \\
\quad+\left(1-\frac{\widehat{k}(r-m)}{\bar{k}}\right) \cdot\left(p_{c}(r-m) \cdot w^{C}+\left(1-p_{c}(r-m)\right) \cdot w\right) .
\end{aligned}
\end{aligned}
$$

The following proposition gives the result of this budgetary trade-off:

Proposition 1 The optimal competition policy always involves both cartel fighting and controlling mergers. The optimal investment in merger control $m^{*}$ is such that $0<m^{*}<r$.

Let us explain this result. First of all, note that it is never optimal to spend the whole budget on merger control $\left(m^{*}<r\right)$ since then the CA will clear the inefficient mergers even if the true merger type is observed (see Lemma 1). In that case, there would be a positive gain from reducing the merger control expenditure. However, spending more on cartel fighting $(c>\widehat{c})$ will soon cause the gain from merger control to become positive, since the CA will now prevent $\underline{e}$-mergers and thus avoid welfare losses. Thus, for $c>\widehat{c}$, the CA will face a trade-off between enforcing tougher cartel fighting at the cost of lowering the quality of merger control (lower $m$, i.e. $m<r$ ). In order to determine the outcome of this trade-off, let us assess the marginal impact of a stricter merger control (higher $m$ ) on the expected welfare ${ }^{16}$ :

$$
\begin{aligned}
\frac{\partial E W(m)}{\partial m} & =\underbrace{\begin{array}{c}
\frac{1}{\bar{k}}\left[\widehat{k}^{\prime}(r-m)\left(1-p_{m}(m)\right)+p_{m}^{\prime}(m) \widehat{k}(r-m)\right] \\
{\left[\left(p_{c}(r-m) \cdot w^{c}+\left(1-p_{c}(r-m)\right) \cdot w\right)-w^{M}(\underline{e})\right]}
\end{array}}_{\text {Selection Effect }>0} \\
& +\underbrace{\left(1-\frac{1}{\bar{k}}\left(1-p_{m}(m)\right) \widehat{k}(r-m)\right) p_{c}^{\prime}(r-m)\left(w^{c}-w\right)}_{\text {Detection Effect }<0} .
\end{aligned}
$$

\footnotetext{
${ }^{16}$ The welfare expression leaves out the expected welfare from the efficient type merger since we assumed that its decision to merge does not depend on the CA's policy choice.
} 
The CA's choice of allocating more resources to controlling mergers has two opposite effects on the expected welfare: a selection effect and a detection effect. On the one hand, spending more on merger control enforcement increases the probability of the CA screening the mergers and hence blocking the anticompetitive/type- $\underline{e}$ mergers. This is the so-called 'selection' effect, which, following from Lemma 1 , is welfare-increasing for $c \geq \widehat{c}$. This effect captures the marginal return of merger control, and decreases with the amount spent on controlling mergers. Indeed, the more money allocated to cartel fighting, the higher the incentive for inefficient firms to notify a merger, and thus the higher the benefit from screening mergers. In other words, both branches of antitrust appear to be complementary, since the marginal return of merger control increases with the resources invested in cartel fighting. On the other hand, spending money on merger control always undermines cartel fighting: this is the so-called 'detection' effect, whereby fewer cartels will be detected and punished whenever the CA reduces the budget allocated to fighting them. This effect is welfare-reducing and captures the marginal return of cartel fighting. It also increases in absolute terms with the size of the budget available for merger control. Indeed, the less money spent on merger control, the smaller the population of potential cartels, since more firms merge. This is the other facet of the above-mentioned complementarity between the two antitrust instruments: in particular, if no resources are dedicated to merger control, then all firms are induced to merge and will actually merge. But then the detection effect would be nil, which explains why one cannot have a solution where the whole budget is spent on cartel fighting.

The optimal split in the CA's budget therefore strikes a balance between these two opposite marginal effects, which occurs for $m^{*} \in(0, r)$. In other words, the interior solution obtains due to the complementarity between the two instruments since the $\mathrm{CA}$ is always induced to split its resources between cartel fighting and merger control. We study the robustness of this result w.r.t. the introduction of post-merger cartel formation in the next section.

\section{Post-merger cartel and the impact of merger coordinated ef- fect}

In this section we abandon the assumption that firms choose merger over cartel or vice-versa. As stated in the Introduction, real life examples suggest, on the contrary, that the strategies of horizontal merger and cartel may also be complementary, in particular whenever the horizontal merger is the preliminary stage to an ensuing cartel formation. To account for such situations, 
and to assess their potential impact on the results obtained in the previous section, below we modify our framework in the following way:

Whenever the two firms merge they will later form a cartel with the remaining firm. It is enough to replace 'merger' by 'merger with ensuing cartel' in the game tree displayed in the first section (Figure 1), to obtain the game tree that applies for the extended model studied in the present section. The post-merger cartel will be detected and punished with the same probability as before, $1-p_{c}(c)$. Following the post-merger cartel, the fraction of profit accruing to the two firms is denoted $\pi^{M C}(e)$, whereas the consumer welfare becomes $w^{M C}(e)$. The higher internal stability of post-merger cartels, i.e. the easier coordination when the market becomes more concentrated (see Motta 2004 and Kovacic et al. 2006, 2009) is captured by the profitability of the post-merger profit $\pi^{M C}(e)$ and by the corresponding consumer surplus $w^{M C}(e)$. The higher the cartel stability, i.e. the coordinated effect of the merger, the higher the profit and the lower the surplus ${ }^{17}$.

The timing of our game is unchanged, and as before, we start our analysis by deriving the CA's merger control decision as well as the firms' merger decision in the following lemma:

Lemma 2 (i) If the merger is expected to be cleared at the final stage, there exists a cost threshold $\widetilde{k}(c)$ such that the inefficient merger is notified iff $k \leq \widetilde{k}(c) . \widetilde{k}(c)$ is increasing in $c$ if the merger coordinated effect is small, but decreasing in it otherwise.

(ii) If the CA observes the merger type, the CA blocks the inefficient mergers iff the budget allocated to cartel fighting is larger than a threshold $\widetilde{c}$. Moreover, $\widetilde{c}=0$ for a high enough coordinated effect.

Lemma 2 indicates that the merger's coordinated effect may substantially modify both the CA's merger control decision and the firms' choice between either forming a cartel from the beginning or first merging before engaging in a cartel.

To start with, the severity of the anti-cartel fighting may now have a different effect on the number of potential merger projects, depending on the size of the merger's coordinated effect. For a low coordinated effect, an improvement in the detection of cartels induces more firms to merge, as before. Nevertheless, the opposite obtains for a large enough coordinated effect,

\footnotetext{
${ }^{17}$ While empirical studies indicate that horizontal mergers may likewise lead to higher or lower cartel stability (see Davis and Huse 2009) depending on the future market structure (see for instance Compte, Jenny and Rey, 2002), we focus on the former case, since our objective is to check whether a higher stability of cartels post merger may reverse our initial results.
} 
because the post-merger collusion may simply be the very reason why firms decide to merge in the first place. As a result, the tougher cartel fighting will reduce the benefit of merging, and thus will deter more mergers.

Secondly, a high enough coordinated effect may make the merger control beneficial even if no resources are available for cartel fighting, precisely because firms may now merge in order to form a more stable cartel afterwards. Therefore the merger control enables the CA to prevent the post-merger cartels, and as such yields a positive return even if no resources are invested in cartel fighting itself.

The objective of the CA is now written as follows:

$$
\begin{aligned}
& E W^{\text {coord }}(m)= \\
& \frac{\tilde{k}(r-m)}{\bar{k}}\left[\begin{array}{c}
p_{m}(m) \operatorname{Max}\left(\begin{array}{c}
{\left[\left(p_{c}(r-m) \cdot w^{c}+\left(1-p_{c}(r-m)\right) \cdot w\right)\right]} \\
{\left[p_{c}(r-m) \cdot w^{M C}(\underline{e})+\left(1-p_{c}(r-m)\right) \cdot w^{M}(\underline{e})\right]}
\end{array}\right)+ \\
\left(1-p_{m}(m)\right)\left[p_{c}(r-m) \cdot w^{M C}(\underline{e})+\left(1-p_{c}(r-m)\right) \cdot w^{M}(\underline{e})\right]
\end{array}\right] \\
& +\left(1-\frac{\widetilde{k}(r-m)}{\bar{k}}\right)\left[\left(p_{c}(r-m) \cdot w^{c}+\left(1-p_{c}(r-m)\right) \cdot w\right)\right] .
\end{aligned}
$$

where $E W^{\text {coord }}(m)$ denotes the expected consumer surplus in the presence of a coordinated effect.

The next result shows how the optimal policy mix may change due to the possibility of a post-merger cartel:

Proposition 2 (i) For a small coordinated effect the CA optimally splits its budget between cartel fighting and merger control, i.e. there exists an optimal investment in merger control $m^{* *}$ with $0<m^{* *}<r$;

(ii) A large enough coordinated effect makes the CA optimally spend its whole budget on cartel fighting only $\left(m^{* *}=0\right)$.

In other words, the previous result of Proposition 1 on the optimal budget split between merger control and cartel fighting remains valid only if the coordinated effects is weak enough. Otherwise, the CA should spend all its money on cartel fighting only.

In order to explain the intuition for this result, let us once again consider the role of merger control enforcement on the expected welfare, as described by the marginal effect of merger control given below: 


$$
\begin{aligned}
\frac{\partial E W^{\text {coord }}(m)}{\partial m} & = \\
& \underbrace{\underbrace{p_{c}^{\prime}(r-m)\left[\begin{array}{c}
\left(1-\frac{\widetilde{k}(r-m)}{\bar{k}}\left(1-p_{m}(m)\right)\left(w-w^{C}\right)\right. \\
+\frac{\widetilde{k}(r-m)}{\bar{k}}\left(1-p_{m}(m)\right)\left(w^{M}(\underline{e})-w^{M C}(\underline{e})\right)
\end{array}\right]}_{\text {Selection Effect }} .}_{\begin{array}{c}
\frac{1}{\bar{k}}\left[\widetilde{k}^{\prime}(r-m)\left(1-p_{m}(m)\right)+p_{m}^{\prime}(m) \widetilde{k}(r-m)\right] \\
{\left[\left(p_{c}(r-m) \cdot w^{c}+\left(1-p_{c}(r-m)\right) \cdot w\right)-\left(p_{c}(r-m) w^{M C}(\underline{e})+\left(1-p_{c}(r-m) w^{M}(\underline{e})\right)\right]\right.}
\end{array}}
\end{aligned}
$$

As before, merger control leads to both a selection effect and a detection effect. The detection effect still involves a lower cartel detection as soon as more money is spent on controlling mergers. As such, it remains negative. On the other hand, merger control still enables merger screening and thus avoids some welfare-losses from the inefficient, $\underline{e}$-type mergers. Following Lemma 2 , as long as the coordinated effect is small enough, this effect remains positive. Thus, for a small coordinated effect, the optimal competition policy mix strikes a balance between these two opposite marginal effects, yielding an interior solution for the optimal merger control expenditure $\left(m^{* *}\right.$ positive and below $\left.r\right)$.

However, the importance of the merger coordinated effect modifies the size and even the sign of these two marginal effects. A large enough merger coordinated effect increases the detection effect, because it induces more harmful cartels. This clearly shifts $m^{* *}$ downward. In addition, and following Lemma 2, the selection effect is being reduced by the merger coordinated effect, and may even turn out to be negative if the latter is large enough. Indeed, with a large coordinated effect, and because a tougher merger control means weaker cartel scrutiny, more firms merge in the end despite the higher amount of resources allocated to controlling mergers. Therefore this large coordinated effect makes the marginal return of merger control negative, and thus the optimal policy will consist in investing only in cartel fighting. In other words, here one obtains a switch from the former complementarity to actual substitutability between the two antitrust branches in the event of a sufficiently large merger coordinated effect. To see this, note that such a large coordinated effect induces the $\mathrm{CA}$ to privilege above all the prevention of post-merger cartels. But then any policy mix between the two antitrust instruments is sub-optimal, precisely by not completely avoiding these worst welfare-reducing post-merger cartels. Instead, the CA may prevent them either by spending all its money on merger control so as to block all inefficient mergers later turning into these highly harmful cartels, or by directly investing only in cartel 
fighting. The expected welfare comparison between these two alternatives shows that the cartel fighting dominates. This is due to the fact that mergers, albeit anticompetitive, still yield some cost savings, whereas cartels never do. In other words, the $\mathrm{CA}$ is better off detecting cartels while clearing anticompetitive/low-efficiency mergers, rather than banning these mergers at the cost of leaving post-merger cartels undetected.

\section{Conclusion}

This paper examines the optimal enforcement competition policy mix in terms of merger control and anti-cartel policies, given that the observation of real-life market behavior indicates that firms typically react to the current enforcement focus of the competition agencies (either against mergers or cartels). When studying the interaction between the enforcement of merger control and that of cartel fighting, we accounted for the resulting incentives for firms, as well as for the budget constraint of the competition agency.

When mergers and cartels are substitutable from the point of view of firms (i.e. they choose one over the other), we obtain that the CA will simultaneously enforce both branches of competition policy. This may change if one assumes that merger and cartel are complementary, as happens when firms merge first and then engage in collusion. In this case, if the merger's coordinated effect is large enough, i.e. the post-merger cartel is easy enough to sustain, then the CA will invest all available resources available in cartel fighting alone, because we show that the two instruments are substitutes and cartel fighting is more efficient.

\section{REFERENCES}

Aubert, C. and J. Pouyet (2004) "Competition policy, regulation and the institutional design of industry supervision", Louvain Economic Review 70(2), p. 153-168

Bensaid, B., D. Encaoua and A. Perrot (1995) "Separating the Regulators to Reduce Risks Due to Overlapping Control", cahiers Eco\&maths 95.36 - Université de Paris I Panthéon Sorbonne

Bittlingmayer, G. (1985) "Did Antitrust Policy Cause the Great Merger Wave?", Journal of Law and Economics, Vol. 28, No. 1, p. 77-118

Compte, O., Jenny F. and P. Rey (2002) "Capacity Constraints, Mergers and Collusion", European Economic Review 46(1), p.1-29 
Davis, P.J. and C. Huse (2010) "Estimating the 'Coordinated Effects' of Mergers", Working Paper of the Competition Commission, UK, available at

http://www.competition-commission.org.uk/our_role/analysis/Peter\%20Davis_Cristian\%20Huse_2010.pdf

Evenett, S.J, M. C. Levenstein and V.Y. Suslow (2001) "International Cartel Enforcement: Lessons from the 1990s", The World Economy, Vol. 24, N. 9, p. 1221-1245

Farrell, J. and C. Shapiro (1990) "Horizontal mergers: an equilibrium analysis", American Economic Review 80(1), p.107-126

Harrington, J.E. (2011) "When is an antitrust authority not aggressive enough in fighting cartels?", International Journal of Economic Theory, forthcoming (doi: 10.1111/j.17427363.2010.00148.x)

Kovacic, W., R.C. Marshall., L.M. Marx and S.P. Schulenberg (2006) Coordinated Effects in Merger Review: Quantifying the Payoffs from Collusion International Antitrust Law \& Policy: Fordham Corporate, ed. B. Hawk. (Juris Publishing), Chapter 13, p. 271-285

Kovacic, W.E., R.C. Marshall, L.M. Marx, and S.P. Schulenberg (2009) "Quantitative Analysis of Coordinated Effects", Antitrust Law Journal 76(2), p. 397-430

Mehra, P. (2008) "Choice between Cartels and Horizontal Mergers", mimeo

Motta, M., 2004, "Competition Policy: Theory and Practice", Cambridge University Press

Mueller, D.C. (1996) "Antimerger Policy in the United States: History and Lessons", Empirica 23, p. 229-253

Sørgard, L. (2009) "Optimal Merger Policy: Enforcement vs. Deterrence", Journal of Industrial Economics 57(3), p. 438-456

Symeonidis, G. (2002), The Effects of Competition: Cartel Policy and the Evolution of Strategy and Structure in British Industry, Cambridge, MA, MIT Press

\section{Appendix}

\section{Proof of Lemma 1.}

(i) The $\underline{e}$ firms choose to merge iff $p_{c}(c) \pi^{C}+\left(1-p_{c}(c)\right) \pi<\pi^{M}(\underline{e})-k \Leftrightarrow$ $k<\widehat{k}(c)=\pi^{M}(\underline{e})-\left(p_{c}(c) \pi^{C}+\left(1-p_{c}(c)\right) \pi\right)$. This cost threshold is increasing with $c$ : $\frac{\partial \widehat{k}(c)}{\partial c}=-\underbrace{p_{c}^{\prime}(c)}_{<0} \cdot \underbrace{\left(\pi^{C}-\pi\right)}_{>0}>0$. 
(ii) If the CA observes the true merger type, then type $\bar{e}$ is cleared while type $\underline{e}$ is blocked iff $p_{c}(c) w^{C}+\left(1-p_{c}(c)\right) w>w^{M}(\underline{e})$. Note that the LHS of this condition is continuous and increasing with $c$. In addition, for high enough $c$ (i.e. $m \rightarrow 0$ ) the merger is blocked since $p_{c}(r)=0$, whereas for $c=r$ the merger is cleared. Therefore there exists a threshold in terms $\widehat{c}$ such that the merger is blocked iff $c>\widehat{c}$.

\section{Proof of Proposition 1.}

For $c \geq \widehat{c}$, the interior optimal choice of merger control spending (denoted $\mathbf{m}$ ) is defined by: $\frac{\partial E W(m)}{\partial m}=0$

$$
\begin{aligned}
& \Leftrightarrow \underbrace{\left(\frac{\widehat{k}^{\prime}(r-m)}{\bar{k}}\left(1-p_{m}(m)\right)+\frac{\widehat{k}(r-m)}{\bar{k}} p_{m}^{\prime}(m)\right)}_{>0} \cdot \underbrace{\left(p_{c}(r-m) \cdot w^{C}+\left(1-p_{c}(r-m)\right) \cdot w-w^{M}(\underline{e})\right)}_{>0} \\
& +(1-\frac{\widehat{k}(r-m)}{\bar{k}}\left(1-p_{m}(m)\right) \underbrace{p_{c}^{\prime}(r-m)}_{<0} \cdot\left(w^{C}-w\right)=0,
\end{aligned}
$$

since the SOC writes $\frac{\partial^{2} E W(m)}{\partial m^{2}}=$

$\left(-2 \frac{\widehat{k}^{\prime}(r-m)}{\bar{k}} p_{m}^{\prime}(m)\right) \cdot\left(p_{c}(r-m) \cdot w^{C}+\left(1-p_{c}(r-m)\right) \cdot w-w^{M}(\underline{e})\right)$

$+2\left(\frac{\widehat{k}(r-m)}{\bar{k}} p_{m}^{\prime}(m)+\frac{\widehat{k}^{\prime}(r-m)}{\bar{k}}\left(1-p_{m}(m)\right)\right) p_{c}^{\prime}(r-m)\left(w-w^{C}\right)<0$

thanks to our initial assumptions on $F, p_{c}, k$ and $p_{m}$.

Instead, for $c<\widehat{c}$ one has that $\frac{\partial E W(m)}{\partial m}<0$ following from Lemma 1.

To sum up, the optimal merger control expenditure $m^{*}$ is defined by $\operatorname{Min}(\mathbf{m}, r-\widehat{c}) \in(0, r)$.

\section{Proof of Lemma 2.}

(i) The $\underline{e}$ firms choose to merger iff

$$
\begin{aligned}
& \left.p_{c}(c) \pi^{M C}(\underline{e})+\left(1-p_{c}(c)\right) \pi^{M}(\underline{e})\right)-k \geq p_{c}(c) \pi^{C}+\left(1-p_{c}(c)\right) \pi \\
& \left.\Leftrightarrow k \geq \widetilde{k}(c)=\left[p_{c}(c) \pi^{M C}(\underline{e})+\left(1-p_{c}(c)\right) \pi^{M}(\underline{e})\right)\right]-\left[p_{c}(c) \pi^{C}+\left(1-p_{c}(c)\right) \pi\right] .
\end{aligned}
$$

Let us now study the monotonicity of $\widetilde{k}(c)$ :

$$
\frac{\partial \widetilde{k}(c)}{\partial c}=\underbrace{\frac{\partial p_{c}(c)}{\partial c}}_{<0} \cdot[\underbrace{\left(\pi^{M C}(\underline{e})-\pi^{M}(\underline{e})\right)}_{>0}-\underbrace{\left(\pi^{C}-\pi\right)}_{>0}] \text {. Therefore } \frac{\partial \widetilde{k}(c)}{\partial c}>0 \text { if } \pi^{M C}(\underline{e})-\pi^{M}(\underline{e})<
$$

$\pi^{C}-\pi$. Otherwise, $\frac{\partial \widetilde{k}(c)}{\partial c}<0$ (meaning for a large enough coordinated effect such that $\pi^{M C}(\underline{e})>$ $\left.\pi^{M}(\underline{e})+\pi^{C}-\pi\right)$. 
(ii) If the CA observes the true merger type, it will ban the $\underline{e}$-merger if $G(c)=\left[w^{M}(\underline{e}) \cdot\left(1-p_{c}(c)\right)+w^{M C}(\underline{e}) \cdot p_{c}(c)\right]-\left[w \cdot\left(1-p_{c}(c)\right)+w^{C} \cdot p_{c}(c)\right]<0 . G(c)$ is decreasing in $c$ for a small coordinated merger effect $\left(w^{M C}(\underline{e})>w^{M}(\underline{e})+w^{C}-w\right)$. In other words, for a small coordinated effect, there exists a threshold $\widetilde{c}$ such that the CA bans the $\underline{e}$-mergers for $c>\widetilde{c}$ (ensuring $G(c)<0$ ). Instead, for a very large coordinated effect, such that $w^{M C}(\underline{e})<w^{C}$ for instance, $G$ is always negative, meaning that $\widetilde{c}=0$.

\section{Proof of Proposition 2.}

For a small coordinated effect (i.e. for small $\pi^{M C}(\underline{e})$ ), the optimal merger control expenditure $m^{* *}$ is given by the $\operatorname{Min}(\mathbf{m}, r-\widetilde{\mathbf{c}})$ where $\mathbf{m}$ solves the FOC: $\frac{\partial E W^{\text {coord }}(\mathbf{m})}{\partial m}=0$.

Indeed, for a small coordinated effect $\left(w^{M C}(\underline{e})\right.$ such that $\left.w^{M}(\underline{e})-w^{M C}(\underline{e})<w-w^{C}\right)$, the SOC is satisfied:

$$
\begin{aligned}
& \frac{\partial^{2} E W^{\text {coord }}}{\partial m^{2}}= \\
& \underbrace{\left[\left(w-w^{C}\right)-\left(w^{M}(\underline{e})-w^{M C}(\underline{e})\right)\right]}_{>0} 2 \underbrace{p_{c}^{\prime}(r-m)}_{<0} \underbrace{\left(\frac{\widetilde{k}^{\prime}(r-m)}{\bar{k}}\left(1-p_{m}(m)\right)+\frac{\widetilde{k}(r-m)}{\bar{k}} p_{m}^{\prime}(m)\right)}_{>0} \\
& -\underbrace{2\left[\left(p_{c}(r-m) w^{C}+\left(1-p_{c}(r-m)\right) w\right)-\left(p_{c}(r-m) w^{M C}(\underline{e})+\left(1-p_{c}(r-m)\right) w^{M}(\underline{e})\right)\right]}_{>0} \\
& \cdot \underbrace{\frac{\widetilde{k}^{\prime}(r-m)}{\bar{k}} p_{m}^{\prime}(m)}_{>0}<0 .
\end{aligned}
$$

Moreover, we have $0<m^{* *}<r$, since $\frac{\partial E W^{\text {coord }}(m=0)}{\partial m}>0$ for such a low coordinated effect.

Instead, the SOC is no longer satisfied for a large enough coordinated effect. Let us then determine the value of $m$ maximizing $E W^{\text {coord }}$ in that case.

Note first that function $E W^{\text {coord }}(m)$ admits a maximum on the interval $[0, r]$ because the function is continuous on that interval.

Note also that for $0<m<r, E W^{\text {coord }}(m)$ decreases with the coordinated effect (lower $\left.w^{M C}(e)\right): \frac{\partial E W^{\text {coord }}(m)}{\partial w^{M C}}=\frac{\widetilde{k}(r-m)}{\bar{k}}\left(1-p_{m}(m)\right) \cdot p_{c}(r-m)>0$.

Moreover, $E W^{\text {coord }}(m)$ is higher for $m=0$ than for $m=r$ :

$E W^{\text {coord }}(m=0)=\frac{\widetilde{k}(r)}{\bar{k}} w^{M}(\underline{e})+\left(1-\frac{\widetilde{k}(r)}{\bar{k}}\right) w>E W^{\text {coord }}(m=r)=w^{C}$

As a result, the optimal solution $m^{* *}$ switches from the previous interior solution to the corner solution $m^{* *}=0$ for a sufficiently large coordinated effect. 


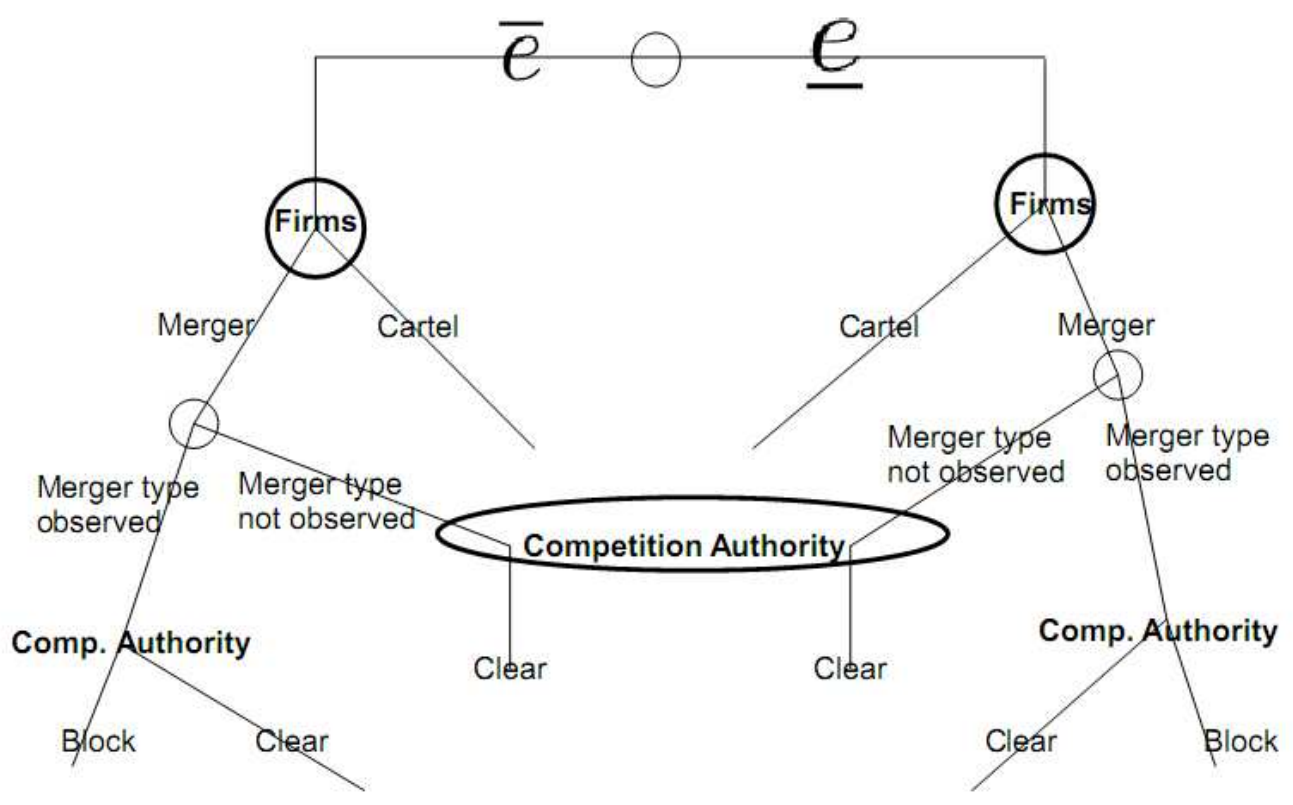

